\title{
Trends in colorectal cancer mortality in Europe: retrospective analysis of the WHO mortality database
}

\author{
Driss Ait Ouakrim, ${ }^{1}$ Cécile Pizot, ${ }^{2}$ Magali Boniol,, ${ }^{2}$ Matteo Malvezzi, ${ }^{3}$ Mathieu Boniol, 2,4 Eva Negri, ${ }^{5}$ \\ Maria Bota, ${ }^{2,4}$ Mark A Jenkins, ${ }^{1}$ Harry Bleiberg, ${ }^{6}$ Philippe Autier ${ }^{4,7}$
}

${ }^{1}$ Centre for Epidemiology and Biostatistics, Melbourne School of Population and Global Health, University of Melbourne, Melbourne, Australia

2Department of Biostatistics, International Prevention

Research Institute, Lyon, France ${ }^{3}$ Department of Clinical Sciences and Community Health, Universitá degli Studi di Milano, Milan, Italy

¿University of Strathclyde Institute for Global Public Health at iPRI, Lyon, France

${ }^{5}$ Department of Epidemiology, IRCCS (Istituto di Ricerche Farmacologiche Mario Negri), Milan, Italy

${ }^{6} J$ ules Bordet Institute, Brussels, Belgium

7Department of Population Research, International

Prevention Research Institute, 69006 Lyon Cedex 08, France

Correspondence to:

PAutier philippe.autier@i-pri.org Additional material is published online only. To view please visit the journal online (http://dx.doi. org/10.1136/bmj.h4970)

Cite this as: BMJ 2015;351:h4970 doi: 10.1136/bmj.h4970

Accepted: 28 August 2015

\section{ABSTRACT}

OBJECTIVE

To examine changes in colorectal cancer mortality in

34 European countries between 1970 and 2011.

DESIGN

Retrospective trend analysis.

\section{DATA SOURCE}

World Health Organization mortality database.

\section{POPULATION}

Deaths from colorectal cancer between 1970 and 2011. Profound changes in screening and treatment efficiency took place after 1988; therefore, particular attention was paid to the evolution of colorectal cancer mortality in the subsequent period.

\section{MAIN OUTCOMES MEASURES}

Time trends in rates of colorectal cancer mortality, using joinpoint regression analysis. Rates were age adjusted using the standard European population.

\section{RESULTS}

From 1989 to 2011, colorectal cancer mortality increased by a median of $6.0 \%$ for men and decreased by a median of $14.7 \%$ for women in the 34 European countries. Reductions in colorectal cancer mortality of more than $25 \%$ in men and $30 \%$ in women occurred in Austria, Switzerland, Germany, the United Kingdom, Belgium, the Czech Republic, Luxembourg, and Ireland. By contrast, mortality rates fell by less than $17 \%$ in the Netherlands and Sweden for both sexes. Over the same period, smaller or no declines occurred in most central European countries. Substantial mortality increases occurred in Croatia, the former

\section{WHAT IS ALREADY KNOWN ON THIS TOPIC}

Colorectal cancer is a major public health issue in most western countries

Since 1989, many European countries have undergone changes in the prevalence of risk factors for colorectal cancer (such as obesity and alcohol intake), participation in screening programmes, and access to specialised care and effective treatments

\section{WHAT THIS STUDY ADDS}

Colorectal cancer mortality is falling in an increasing number of European countries, despite persistent differences between men and women and between specific regions in Europe

In 1989-2011, the largest reductions in colorectal cancer mortality were observed in countries with increased screening participation and improved access to specialised care; in most central European countries, mortality has been stable or slightly decreasing since the early 2000 s, but is still increasing in most eastern European countries

Strategies already in place in several European countries could be used as models to design and implement effective health policies to prevent death from colorectal cancer
Yugoslav republic of Macedonia, and Romania for both sexes and in most eastern European countries for men. In countries with decreasing mortality, reductions were more important for women of all ages and men younger than 65 years. In the 27 European Union member states, colorectal cancer mortality fell by $13.0 \%$ in men and $27.0 \%$ in women, compared with corresponding reductions of $39.8 \%$ and $38.8 \%$ in the United States.

\section{CONCLUSION}

Over the past 40 years, there has been considerable disparity in the level of colorectal cancer mortality between European countries, as well as between men and women and age categories. Countries with the largest reductions in colorectal cancer mortality are characterised by better accessibility to screening services, especially endoscopic screening, and specialised care.

\section{Introduction}

Colorectal cancer is the second most commonly diagnosed cancer in the world and has poor prognosis when metastasised to lymph nodes or distant organs. After lung cancer, it is the most common cause of cancer death in Europe. In 2012, it was estimated that 241600 European men were diagnosed with colorectal cancer, and that 113200 men died from the disease. For European women, 205200 cases of colorectal cancer and 101500 related deaths were recorded that year. ${ }^{1}$

Over the past two decades in Europe, early detection of colorectal cancer has increased through screening and easier access to endoscopic removal of adenomatous polyps (the most common precursor lesion). ${ }^{2}$ At the same time, new treatments have been developed and their availability improved. Several reports have shown that colorectal cancer mortality has been steadily decreasing for at least two decades in several high income countries such as the United States ${ }^{34}$ and Japan. ${ }^{5}$ A similar pattern has also been observed in Europe, with declining mortality trends since the early 1980s and 1990s for men and women, respectively. ${ }^{67}$ These studies also highlighted important disparities between countries, particularly between northwest Europe (where the earliest and largest declines were observed) and the rest of Europe.

In this study, we analysed data on colorectal cancer mortality from 34 European countries between 1970 and 2011 by age and sex. Following the lead of previous articles that focused on major European countries, ${ }^{6}$ our aim was to expand on their findings and provide up to date, long term temporal trends of colorectal cancer mortality for all European countries. We also examined recent mortality trends in relation to levels in 1989-91, before the advent of more efficient patient management 
and expansion of screening activities. For the sake of comparison, we performed a similar analysis of corresponding mortality data in the 27 European Union member states (as one group) and the USA.

\section{Methods}

\section{Mortality data}

The number of deaths from colorectal cancer was obtained from the World Health Organization mortality database for 34 European countries and the USA for the period 1970-2011. ${ }^{8}$ The WHO mortality database provides annual data on mortality statistics by age, sex, and cause of death as obtained by national registration systems. A detailed assessment of data completeness and quality has been conducted by Mathers and colleagues. ${ }^{9}$

Between 1970 and 2011, data on cause of death was classified by use of three versions of the international classification of diseases (ICD, 8th to 10th revisions). We defined colorectal cancer mortality as any death with an ICD-8 code of A048-A049, ICD-9 code of B093-B094, or ICD-10 code of C18-C21. We also included any death with an ICD code for cancers of the anus or anal canal because it was unclear from the database how some countries used the different ICD coding schemes to classify cancers into the various subsites of colorectal cancer: "colon," "recto-sigmoid junction," "rectum," "anus," and "anal canal."

For the majority of countries, data were available for most or all of the period of interest. Cyprus was not included because data were only available for four years (1999, 2000, 2004, 2006). For Switzerland, data were available only until 2010. Furthermore, a change in coding practice in 1994 resulted in an over-reporting of cancer mortality before 1994 . We therefore applied a correction factor of 0.94 to all mortality rates before 1995, as recommended by Lutz and colleagues. ${ }^{10}$ For most central and eastern European countries, data were available since the early to mid-1980s until 2009-10apart from Bulgaria, for which data were available for the entire period. For Slovakia and the former Yugoslav republic of Macedonia, data were available from 1991 and 1992, respectively, until 2010. Web table 1 lists the specific years with missing data for each country.

\section{Patient involvement}

No patients were involved in setting the research question or the outcome measures, nor were they involved in the design and implementation of the study. There are no plans to involve patients in dissemination.

\section{Statistical analyses}

We used the direct method and age specific population estimates from the WHO mortality database $\mathrm{e}^{8}$ to compute age adjusted mortality rates of colorectal cancer, according to the age distribution of the standard European population. ${ }^{11}$ Joinpoint regression analysis was performed over the whole period to identify years when significant changes in mortality rates occurred. We then calculated annual percent changes (relative change) for each country, by fitting a regression line to the natural logarithm of the rates on the period 1989-2011 and over the last five years of available data (2007-2011). Because of missing data, regression was fitted over the periods 1992-2010 for Slovakia and 1991-2010 for Macedonia. Based on the underlying joinpoint model, overall percent changes were then derived for the period 1989-2011.

We conducted these analyses separately for men and women of all ages, and for specific age categories $(<65$, $65-79$, and $\geq 80$ years). We used these age groups for three main reasons. Firstly, 65 years is the maximal legal retirement age in most European countries, which implies potential changes in lifestyle factors, screening, and access to treatment. Secondly, most colorectal cancers are diagnosed in people aged 65-79 years. And thirdly, patients with the disease aged 80 years and older require specific treatment modalities and often have more adverse events (including death) related to treatment than younger populations. ${ }^{1213}$ We undertook all joinpoint regression analysis using the publicly available joinpoint software from the surveillance research programme of the US National Cancer Institute. ${ }^{14}$ Web table 2 lists the modelling parameters.

\section{Results}

Figures 1 and 2 provide an overview of the evolution of colorectal cancer mortality by sex and for all ages between 1970 and 2011 (or the last year of available data). Web figures 1-3 show the mortality trends by age $(<65,65-79$, and $\geq 80$ years). Important differences in colorectal cancer mortality exist between countries. Large declines in mortality occurred in northern and western European countries. We observed increasing mortality rates mostly in countries in southern, central, and eastern Europe-apart from the Czech Republic, which had one of the largest declines in mortality for both sexes.

We were most interested in the recent trends in colorectal cancer mortality (1989-2011), because the most profound changes in screening and treatment efficiency took place after 1988. Figure 3 summarises the evolution of mortality in 1989-2011 and highlights the diverse results across Europe. Large differences can be observed between men and women and between countries, including those with comparable high level economies.

For example, between 1989 and 2011 in the Netherlands, rates of colorectal cancer mortality fell by only $11.6 \%$ and $16.7 \%$ for men and women, respectively. But in the United Kingdom, Germany, and Austria, the corresponding rates fell by more than $30 \%$ for both sexesdespite the four countries having similar rates as the Netherlands in 1989-91. In the 27 European Union member states, mortality decreased by $13 \%$ for men and $27 \%$ for women.

The largest reductions in colorectal cancer mortality for both sexes occurred in western and northern Europe. Important decreases in mortality also took place in southern European countries and some eastern European countries for women. In central, eastern, and southern European countries, mortality rose until later years. In 1989-91, the highest mortality rates were in Hungary, Slovakia, and the Czech Republic. In other countries, mortality trends stabilised or showed first signs of decline after 2000. 


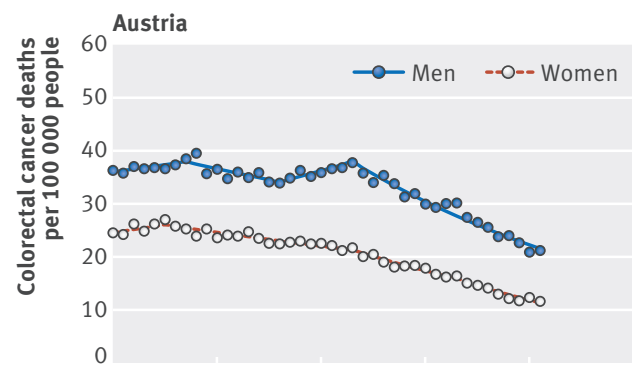

Belarus
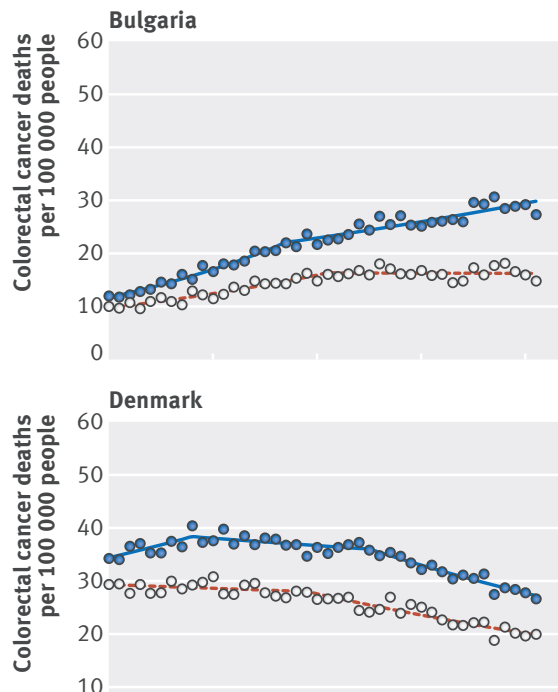

10

0
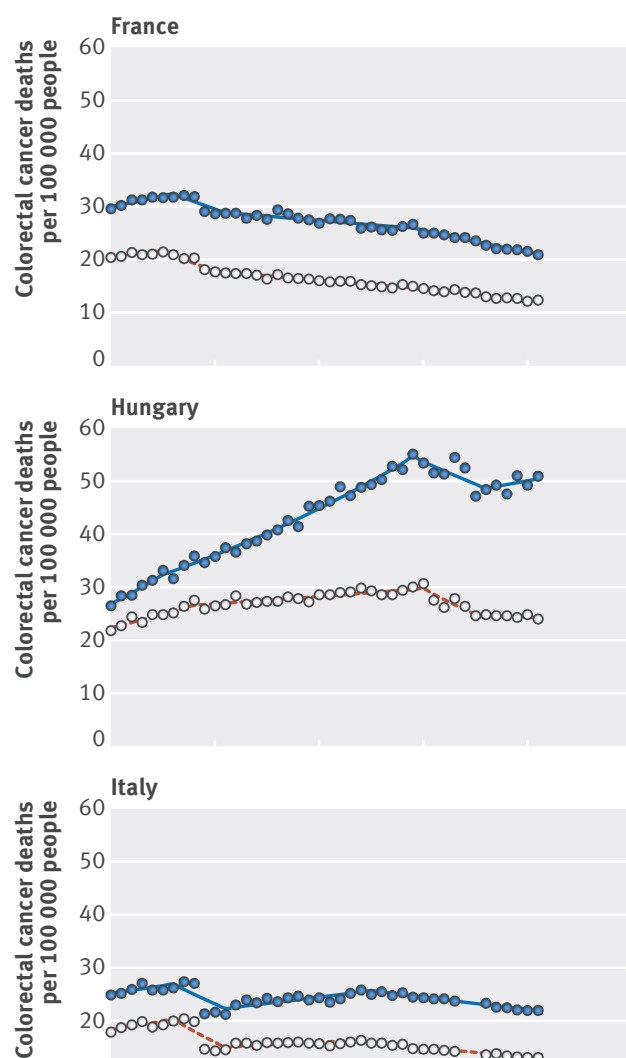

10

$\begin{array}{ccccc}0 & & & & \\ 1970 & 1980 & 1990 & 2000 & 2010\end{array}$

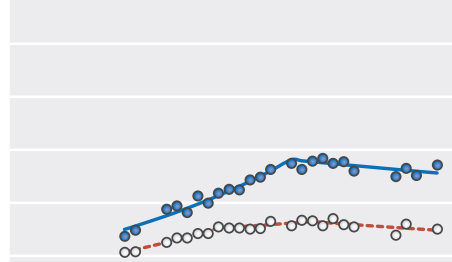

Croatia

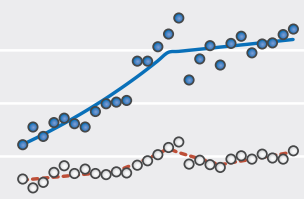

Estonia

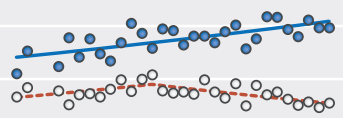

Germany

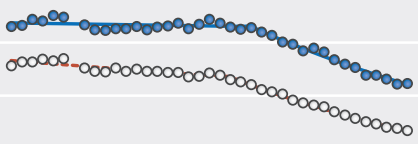

Iceland

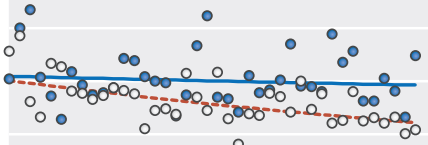

Latvia

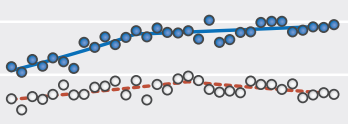

Belgium

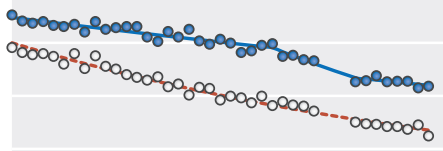

Czech Republic

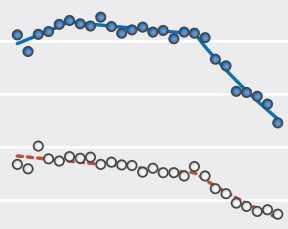

Finland

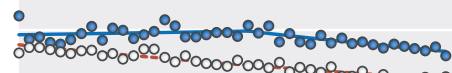

Greece

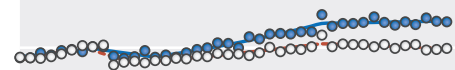

Austria

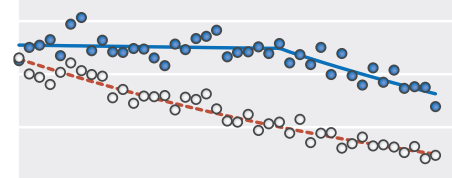

Lithuania

$$
\begin{array}{lllllllllllll}
2020 & 1970 & 1980 & 1990 & 2000 & 2010 & 2020 & 1970 & 1980 & 1990 & 2000 & 2010 & 2020 \\
\text { Year } & & \multicolumn{8}{c}{\begin{array}{c}
\text { Year } \\
\text { Year }
\end{array}}
\end{array}
$$

Fig 1 | Evolution of colorectal cancer mortality in Europe between 1970 and 2011, by sex (Austria to Lithuania) 

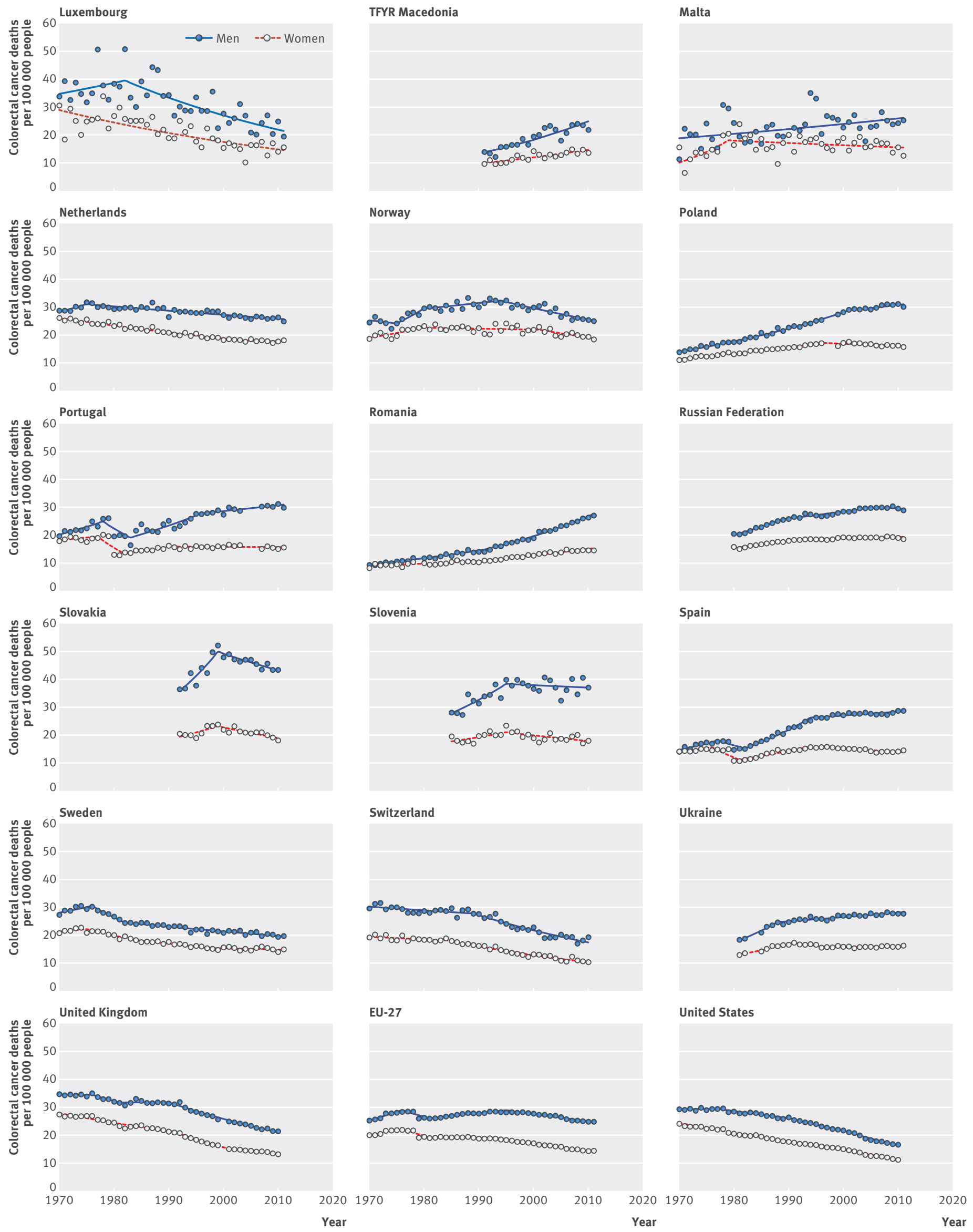

Fig 2 | Evolution of colorectal cancer mortality in Europe between 1970 and 2011, by sex (Luxembourg to USA). EU-27=27 European Union member states
TFYR Macedonia

Malta

Norway

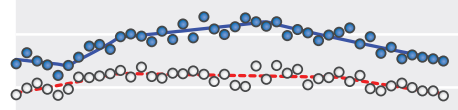

Romania

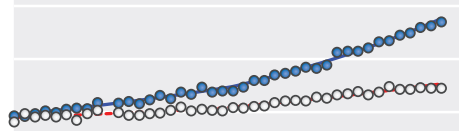

Slovenia

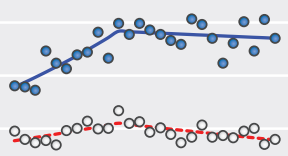

Switzerland
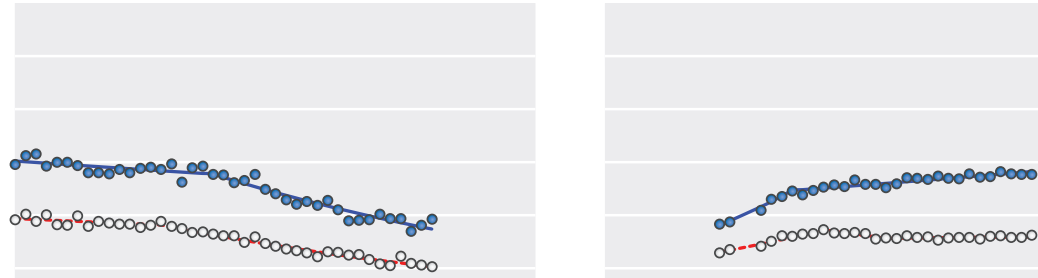

Ukraine

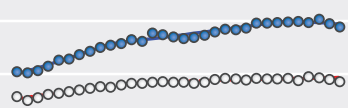

Spain

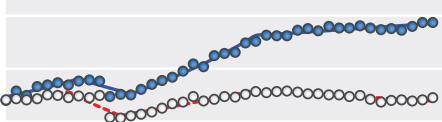

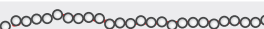

(n) 

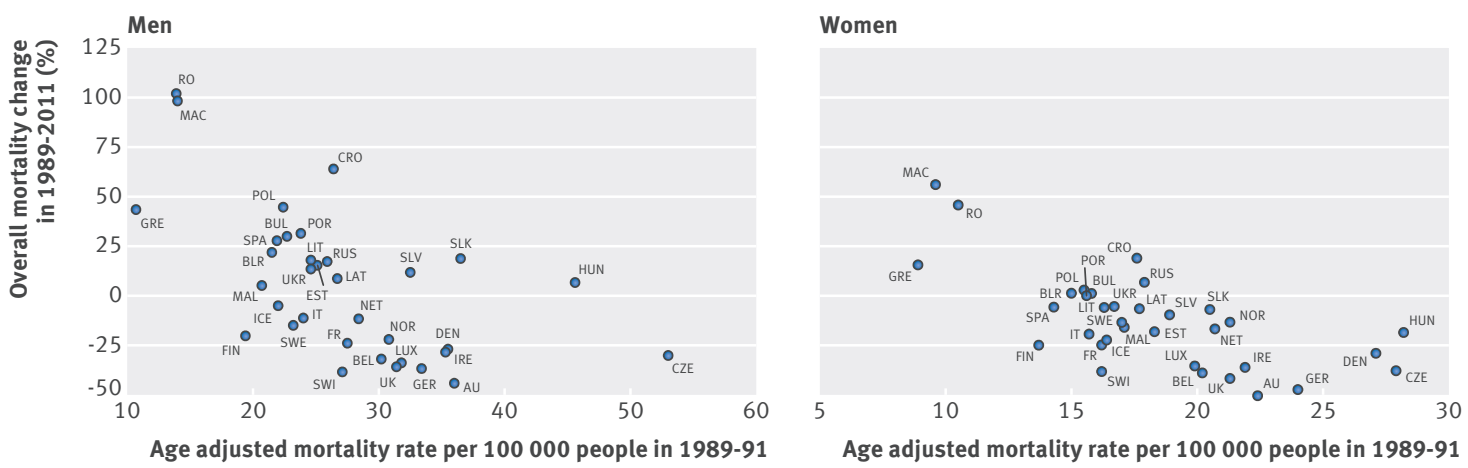

Fig 3 Changes in colorectal cancer mortality between 1989 and 2011 in European countries, according to mean mortality in 1989-91. Data from the USA are not included in the figure. $A U=A u s t r i a ; B E L=B e l g i u m ; B I R=B e l a r u s ; B U L=B u l g a r i a ;$ CRO=Croatia; CZE=Czech Republic; DEN=Denmark; GRE=Greece; EST=Estonia; FIN=Finland; FR=France; GER=Germany; HUN=Hungary; ICE=Iceland; IRE=Ireland; IT=Italy; LAT=Latvia; LIT=Lithuania; LUX=Luxembourg; MAC=Macedonia;

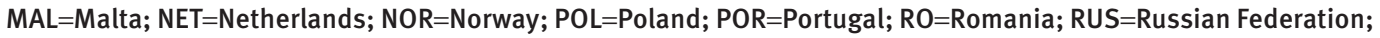
SLK=Slovakia; SLV=Slovenia; SPA=Spain; SWE=Sweden; SWI=Switzerland; UKR=Ukraine; UK=United Kingdom

Sustained mortality increases in both sexes were observed in Latvia, Macedonia, Romania, and the Russian Federation (figs 1 and 2).

Table 1 shows the changes in colorectal cancer mortality for men. In 1989-91, mortality ranged from 10.7 deaths per 100000 people in Greece to 53.0 deaths per 100000 people in the Czech Republic. In 1989-2011, mortality trends ranged from a reduction of $44.1 \%$ in Austria to an increase of $102.0 \%$ in Romania. Mortality decreases of $10 \%$ or more were observed in 15 countries, while increases of $10 \%$ or more were also observed in 15 countries. Average mortality for European men therefore remained constant at 27.3 deaths per 100000 people between 1989-91 and 2009-11. In the later period, however, the mortality difference between the two countries with the highest and lowest mortality rates was reduced from fivefold to threefold.

Table 2 shows the changes in colorectal cancer mortality for women. In 1989-91, mortality rates ranged from 8.9 deaths per 100000 people in Greece to 28.2 per 100000 people in Hungary. In 1989-2011, mortality trends ranged from a reduction of $50.4 \%$ in Austria to an increase of $56.1 \%$ in Macedonia. Mortality decreases of more than $10 \%$ were observed in 20 countries, while increases of $10 \%$ or more were observed in nine countries. The average mortality rate for European women decreased from 18.1 deaths per 100000 people in 1989-91 to 15.3 deaths per 100000 people in 2009-11. Although mortality rates in 1989-91 were on average about one half lower for women than for men, subsequent decreases in mortality in Europe were more pronounced for women. In most countries, reductions in mortality usually started earlier for women than for men; in countries with mortality increases, rates for men were substantially higher than for women.

For all of Europe combined, the reductions in colorectal cancer mortality were more marked for men under age 65 years, whereas reductions for women younger than 80 years were comparable. However, there were major differences in mortality between regions. In most western and northern Europe, decreases were generally more pronounced in people younger than 65 years (tables 1 and 2). But some heterogeneity existed among these countries, because decreases tended to be similar or more important in older people in Germany, Switzerland, the Netherlands, France, and Finland. In central and eastern European countries, people aged 80 years or older had substantial increases in mortality compared with their younger counterparts. In the 27 European Union member states in 2007-11, 6.5\% of all people who died from colorectal cancer were younger than 55 years. In the USA in 1989-2011, mortality fell by $39.8 \%$ for men and $38.8 \%$ for women (tables 1 and 2); mortality decreases were greatest for those aged 65 years or older.

\section{Discussion}

Our study documents the considerable diversity of mortality trends in colorectal cancer across European countries over the past four decades. It shows falling mortality trends for men and women in an increasing number of countries despite persistent differences between the sexes and specific regions in Europe. These results confirm and build on past work by Bosetti and colleagues ${ }^{6}$ using four more years of mortality data and by providing detailed mortality trends for all European countries.

In most countries with falling rates of colorectal cancer mortality, the decrease began between 1970 and up to the mid-1990s. There were sustained reductions in mortality between 1989 and 2011 for most northern, western, and some central European countries. Our results suggest that these reductions are likely to continue and may have been accelerating in the recent past. Our findings also confirm the stabilised mortality trends observed in most central and eastern European countries since the early 2000s, particularly for women and people younger than 65 years. Some of these countries, however, continue to have very high rates, particularly for men. Changes in mortality over time could be due to various factors, including demographic characteristics, lifestyle, disease awareness, screening, and access to effective treatment. 


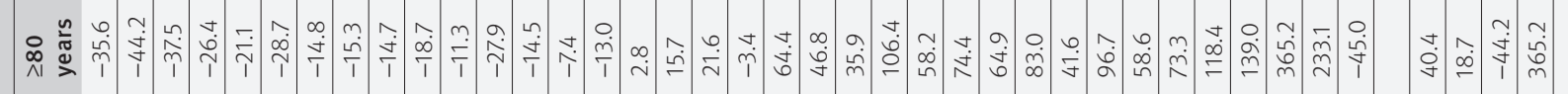

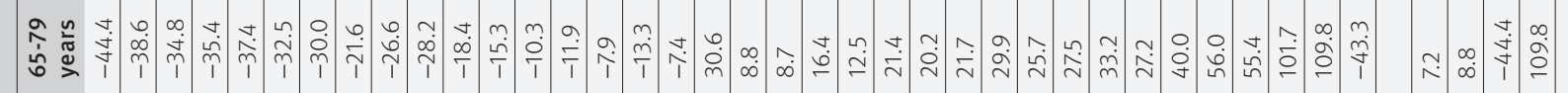

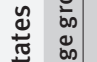

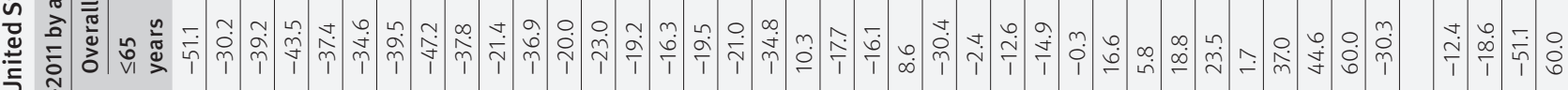

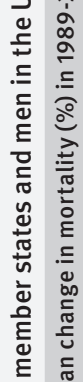

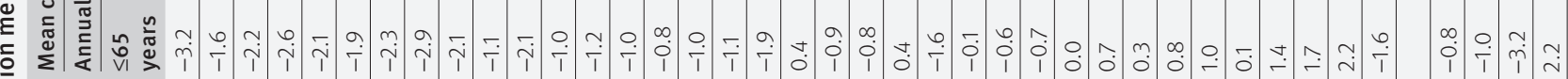

品高竞

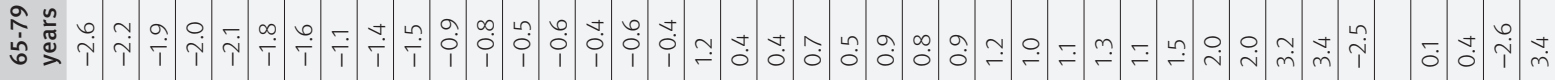
5

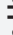

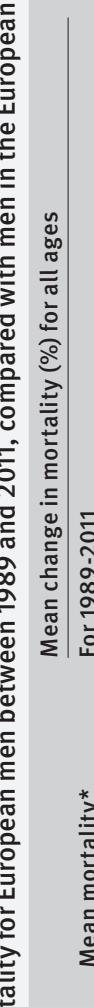

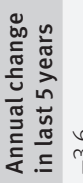

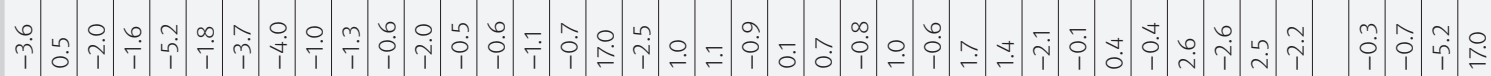

节产

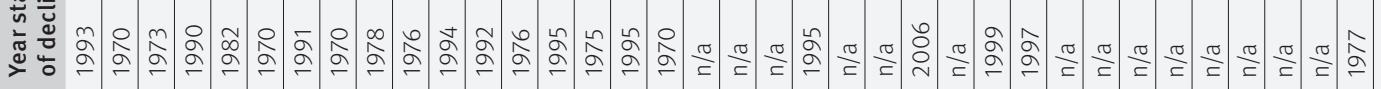

\section{$\overline{\bar{\sigma}}$}

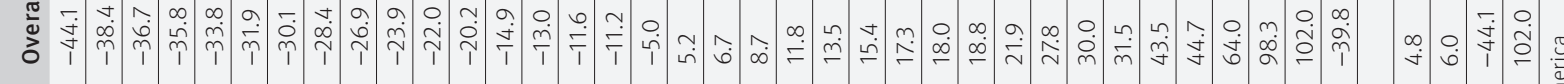

$\stackrel{\sqrt[\pi]{3}}{\stackrel{5}{2}}$

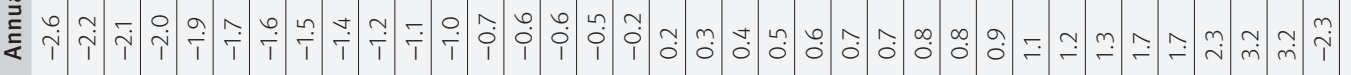

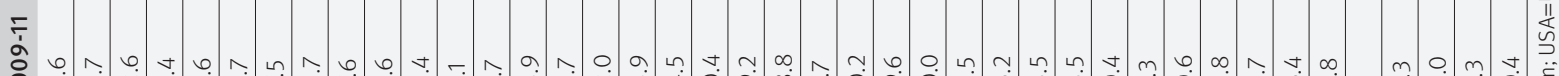

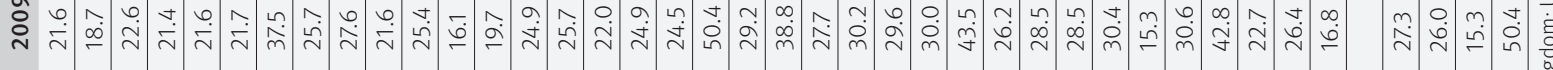

a

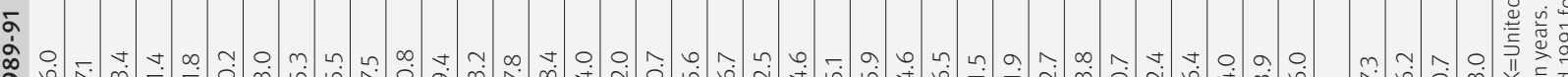

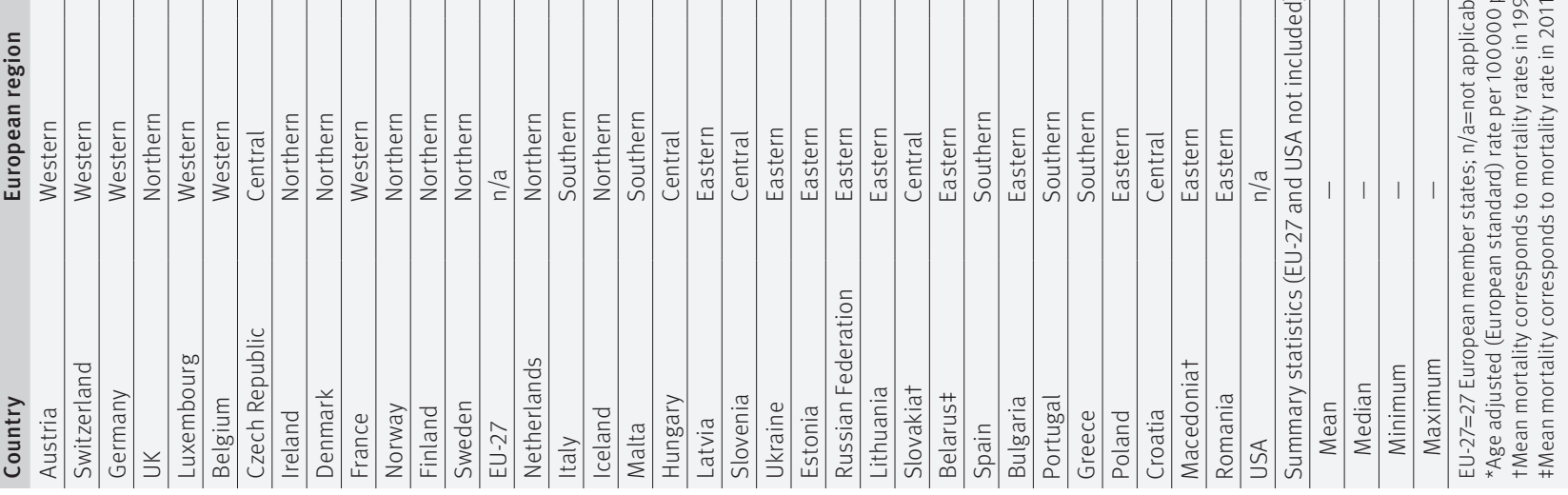

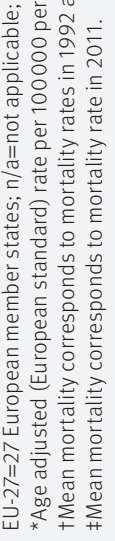




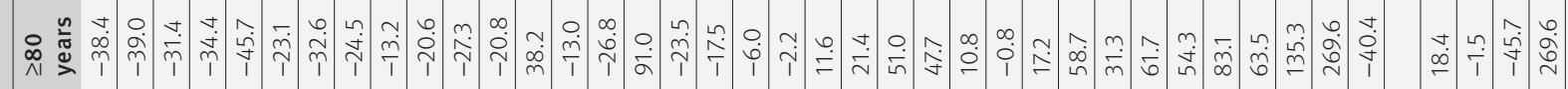

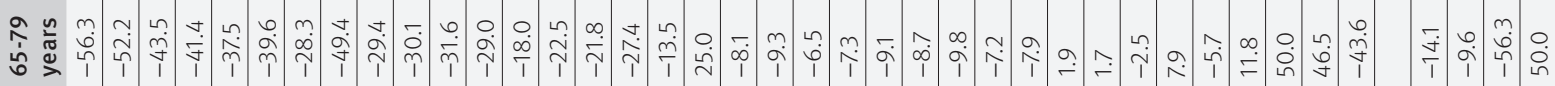

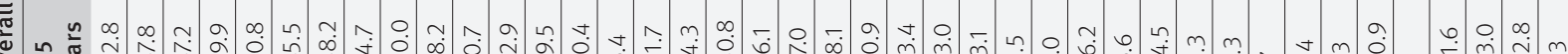

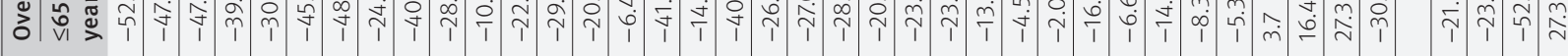

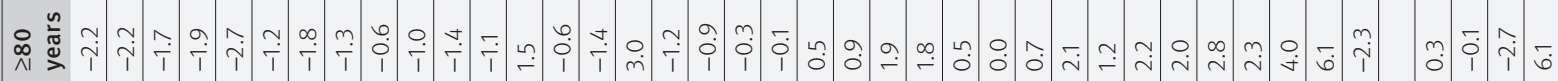

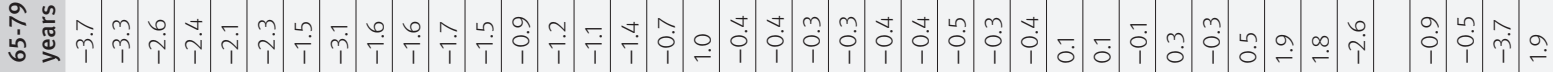

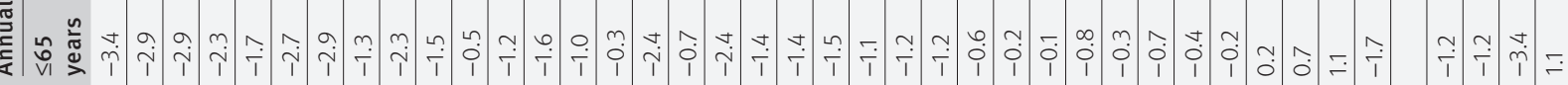

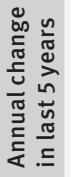

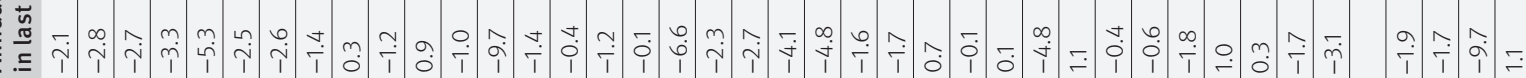

节节

弯

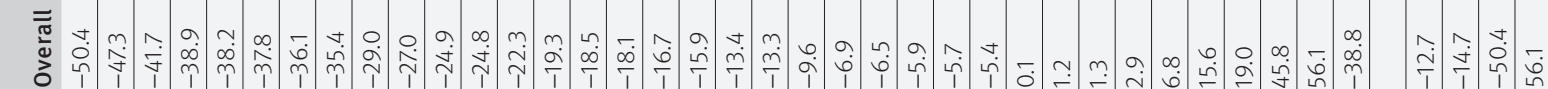

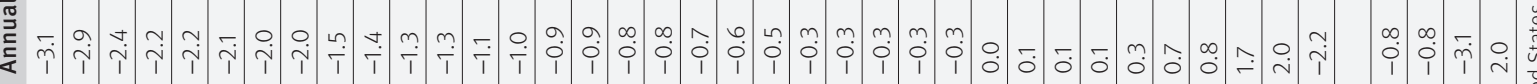

0.9
$c$

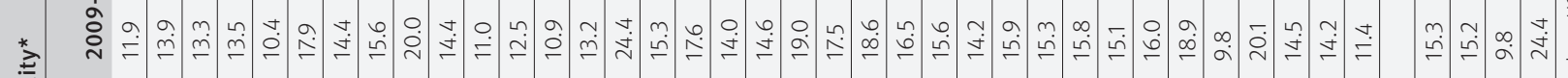

$\bar{\sigma}$

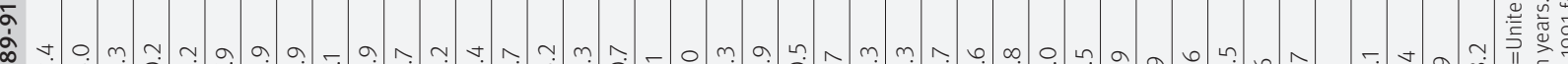

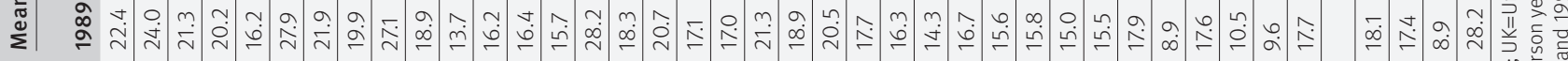

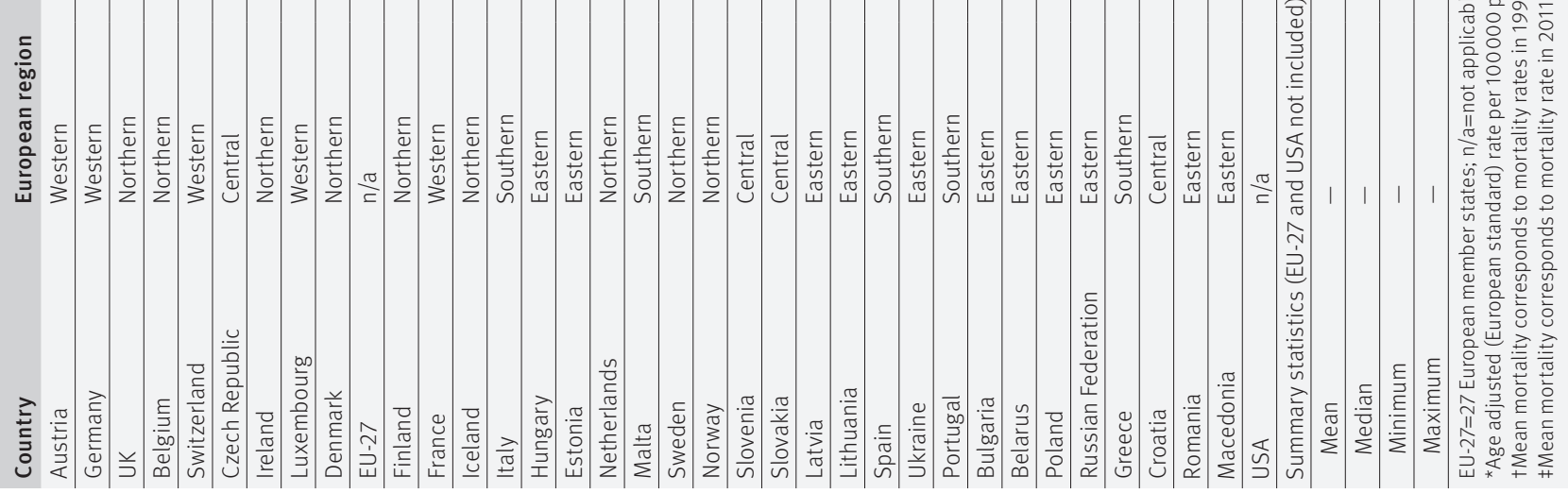


Age and sex specific reductions in colorectal cancer mortality

Reductions in colorectal cancer mortality began earlier and were usually much larger for women. Conversely, in countries where mortality was on the rise, the increases were usually more pronounced for men. Several behavioural and physiological factors have been identified as potential explanations for this difference in the burden of the disease between the sexes. For example, use of oestrogenic hormone by women has been associated with a reduced risk of colorectal cancer. ${ }^{15}$ Furthermore, men are less likely than women to participate in screening. ${ }^{16}$ Men, on average, have less contact than women with the healthcare system, are less well informed about health issues, pay less attention to symptoms, and are less inclined to seek medical advice. ${ }^{1718}$ Men have less varied dietary habits and higher levels of smoking and alcohol consumption than women, which might also be associated with their higher rates of mortality from colorectal cancer. ${ }^{19}$

The considerable differences in age specific trends in colorectal cancer mortality observed across Europe might be related to demographic differences between countries. Older age has been associated with a more advanced stage at diagnosis and less intensive treatment, ${ }^{2021}$ while younger patients with colorectal cancer have a better survival, irrespective of their characteristics, stage at diagnosis, and treatment received. ${ }^{22}$

\section{Lifestyle}

The disparities in colorectal cancer mortality trends could be partly due to contrasting prevalence of lifestyle risk factors across Europe. For instance, several studies have shown that the acute increase in alcohol consumption observed since 1989 in countries of the former Soviet Union is likely to have contributed to the higher incidence and mortality levels of colorectal cancer in those countries. ${ }^{23-25}$ Similarly, the improvement in colorectal cancer mortality rates in younger age groups of some central and eastern European countries could, at least in part, be related to protective lifestyle factors, such as a more diversified diet (for example, containing lower amounts of fat) and reduced alcohol consumption. ${ }^{26}$ This birth cohort phenomenon is perhaps more relevant to central European countries, where dramatic changes in lifestyle have taken place after 1989, potentially leading to decreases in the colorectal cancer burden. ${ }^{2627}$

The so-called Mediterranean diet has been associated with a moderately protective effect against colorectal cancer. ${ }^{28}$ However, lower adherence to this dietary pattern over the past 30 years has been reported in Portugal, Spain, Italy, and Greece, ${ }^{29-32}$ which might be associated with the rising or modestly decreasing rates of colorectal cancer mortality observed in these countries.

Several studies have consistently reported associations between obesity, physical inactivity, and diabetes mellitus, and the occurrence and poor prognosis of colorectal cancer. ${ }^{33-36}$ The prevalence of these risk factors varies substantially between European countries ${ }^{37}$ and tends to increase in many communities. These increasing prevalences might also explain the higher mortality rates observed in some countries and particularly in those where populations have limited access to screening and efficient treatments.

\section{Awareness}

Another potential reason behind the large and early reductions in colorectal cancer mortality observed in some countries is the level of awareness of colorectal cancer among physicians and the public. In our study, nationwide decreases in mortality often started in the 1970s-therefore, at least two decades before the introduction of any screening programme or the diffusion of effective treatments seen in the 1990s. These initial reductions in mortality have been suggested to be due to increasing disease awareness, which spurred patients to consult more quickly for bowel symptoms and doctors to speed up referrals for bowel examination. ${ }^{38}$

\section{Screening}

The publication of randomised trials demonstrating the ability of regular faecal occult blood testing (FOBT) to reduce the risk of death from colorectal cancer ${ }^{3940}$ was the starting point of FOBT based screening activities in several European countries (such as France and the UK). Similarly, sigmoidoscopy trials ${ }^{40}$ and strong and longstanding observational data ${ }^{4142}$ supporting the effectiveness of colonoscopy screening helped establish endoscopy as the primary screening procedure for colorectal cancer in the USA as well as in many European countries (for example, Austria, the Czech Republic, Germany, and Poland). ${ }^{43-45}$

However, it was only until the 2000s that European governments and health authorities set out to engage in more structured screening strategies for colorectal cancer-either through the publication of guideline recommendations or organisation of screening programmes. Currently, all European countries have a system of opportunistic screening (that is, individual initiative or following a doctor's recommendation), organised programmes, or both.

Precise estimates of the effect of screening on colorectal cancer mortality at the population level are rare. Edwards and colleagues recently suggested that $53 \%$ of the reduction in mortality observed in the USA could be explained by screening-colonoscopy being the most widely used procedure. ${ }^{3}$ In European countries, where many organised screening activities have only just begun, there is a shortage of data preventing such an analysis to be conducted. Nonetheless, the limited data available, particularly for European countries with comparable high quality healthcare systems but different levels of screening activity, are consistent with the idea that countries with the largest reductions in colorectal cancer mortality also seem to have the highest levels of screening, particularly with endoscopy. For example, in the Netherlands, ${ }^{46}$ the availability of colonoscopy services is more limited than in France, ${ }^{47}$ Austria, ${ }^{48}$ and Germany. ${ }^{49}$ 
Similarly, limited pilot projects for FOBT screening have been in place in the Netherlands and in Sweden ${ }^{43}$ until 2013. In our analysis, both of these countries achieved relatively modest reductions in colorectal cancer mortality since 1989. A survey of European men and women aged 50 years and older using a standardised questionnaires found that in 2004, the proportion of people who had at least one FOBT over the past 10 years was 61\% in Austria, 53\% in Germany, 24\% in France, $15 \%$ in Sweden, and 4\% in the Netherlands. ${ }^{50}$ For 10 year endoscopic examination of the large bowel, proportions were 24\% in Austria and Germany, 25\% in France, $12 \%$ in Sweden, and $10 \%$ in the Netherlands. These findings strongly suggest that the effect of screening on colorectal cancer incidence and mortality observed in the USA ${ }^{51} 52$ is also taking place across European countries, particularly for those with high levels of endoscopic screening in the population. ${ }^{3}$

\section{Treatment}

New treatments, constant advances in surgical techniques, and therapeutic protocols have also been key in the reduction of colorectal cancer mortality. ${ }^{53}$ There has been an increasing recognition that specialised care, given by medical centres treating large numbers of patients with the same condition, is associated with higher survival rates. ${ }^{545}$ Over the past two decades, the management of patients colorectal cancer has substantially improved, with the introduction of multidisciplinary teams, more accurate staging, novel surgical approaches, and more effective chemotherapy and radiotherapy regimens. ${ }^{56}$

\section{Potential limitations}

Our results should be interpreted with caution because the reliability of death certification can vary between countries. ${ }^{57}$ This means that the quality of WHO mortality data might vary between countries, which in turn might have affected the accuracy of our mortality rates. However, colorectal cancer is a major neoplasm, and its diagnosis and certification are consistent in most European countries. ${ }^{58}$ Therefore, it is unlikely that errors in diagnostic or certification could have significantly affected our findings.

Another potential limitation is that for countries with strongly divergent age specific trends in colorectal cancer mortality, we were unable to determine to what extent those variations were due to changes in the ICD code over the study period. Given these changes in coding practices, we opted for an inclusive approach in defining the anatomical location of colorectal cancer, by taking into account deaths due to cancers of the anus and anal canal in our analysis. These additional cancer sites represent only about $1 \%$ of all cancers of the large bowel. Potential misclassifications would therefore have a very limited effect on our results.

\section{Conclusions}

Overall, since 1970, colorectal cancer mortality has been falling in most European countries. Largest reductions have been observed in western and northern Europe as a result of the combined influence of better public awareness of the disease, reduced prevalence in risk factors such as smoking and alcohol drinking, greater participation to screening, and improved treatment and patient management protocols. However, in southern, central, and eastern Europe-where mortality rates have either risen or modestly decreased-there are clear opportunities for improvement through primary and secondary prevention and better access to specialised care. Effective strategies already in place in several European countries, which have achieved large reductions in colorectal cancer mortality since 1970, represent valuable models for the design and implementation of such public health policies.

Contributors: $\mathrm{PA}, \mathrm{EN}$, and $\mathrm{HB}$ were responsible for the concept of the study. DAO, CP, MB, and MM collected data. DAO, CP, MatB, and MarB analysed the data. DAO, CP, MagB, and MM were responsible for drawing the graphics. Article writing and editing: DAO, MAJ, and PA wrote and edited the article. All the coauthors contributed to the discussion. All authors, external and internal, had full access to all of the data (including statistical reports and tables) in the study and can take responsibility for the integrity of the data and the accuracy of the data analysis. PA is the study guarantor

Funding: The study was mainly funded by the International Prevention Research Institute, Lyon (France). DAO was supported by the Australian National Health and Medical Research Council under the Centre for Research Excellence scheme. Neither organisation had involvement in the design, conduct, and reporting of the study. Competing interests: All authors have completed the ICMJE uniform disclosure form at www.icmje.org/coi_disclosure.pdf and declare: support from the International Prevention Research Institute for the submitted work; no financial relationships with any organisations that might have an interest in the submitted work in the previous three years; no other relationships or activities that could appear to have influenced the submitted work.

Ethical approval: Not required.

Data sharing: Mortality data are publicly available at the WHO mortality database (www.who.int). Additional data from the study are available in the web appendix.

The lead author affirms that this manuscript is an honest, accurate, and transparent account of the study being reported; that no important aspects of the study have been omitted; and that any discrepancies from the study as planned (and, if relevant, registered) have been explained.

This is an Open Access article distributed in accordance with the Creative Commons Attribution Non Commercial (CC BY-NC 4.0) license, which permits others to distribute, remix, adapt, build upon this work non-commercially, and license their derivative works on different terms, provided the original work is properly cited and the use is non-commercial. See: http://creativecommons.org/licenses/ by-nc/4.0/.

1 Ferlay J, Steliarova-Foucher E, Lortet-Tieulent J, et al. Cancer incidence and mortality patterns in Europe: estimates for 40 countries in 2012. Eur J Cancer 2013;49:1374-403

2 Schreuders EH, Ruco A, Rabeneck L, et al. Colorectal cancer screening: a global overview of existing programmes. Gut 2015;64:1637-49.

3 Edwards BK, Ward E, Kohler BA, et al. Annual report to the nation on the status of cancer, 1975-2006, featuring colorectal cancer trends and impact of interventions (risk factors, screening, and treatment) to reduce future rates. Cancer 2010;116:544-73.

4 Jemal A, Bray F, Center MM, Ferlay J, Ward E, Forman D. Global cancer statistics. CA Cancer J Clin 2011;61:69-90.

5 Bosetti C, Malvezzi M, Chatenoud L, Negri E, Levi F, La Vecchia C. Trends in colorectal cancer mortality in Japan, 1970-2000. Int J Cancer 2005;113:339-41.

6 Bosetti C, Levi F, Rosato V, et al. Recent trends in colorectal cancer mortality in Europe. Int / Cancer 2011;129:180-91.

7 La Vecchia C, Gallus S, Fernandez E. Hormone replacement therapy and colorectal cancer: an update. J Br Menopause Soc 2005;11:166-72.

8 World Health Organization. Mortality database. 2013. www.who.int.

9 Mathers CD, Fat DM, Inoue M, Rao C, Lopez AD. Counting the dead and what they died from: an assessment of the global status of cause of death data. Bull World Health Organ 2005;83:171-7. 
10 Lutz JM, Pury P, Fioretta G, Raymond L. The impact of coding process on observed cancer mortality trends in Switzerland. Eur J Cancer Prev 2004:13:77-81.

11 Waterhouse J, Muir C, Correa P, Powel J. Cancer incidence in five continents. Vol III. World Health Organization, 1976.

$12 \mathrm{Au} \mathrm{HJ}$, Mulder KE, Fields AL. Systematic review of management of colorectal cancer in elderly patients. Clin Colorectal Cancer 2003;3:165-71.

13 Papamichael D, Audisio RA, Glimelius B, et al. Treatment of colorectal cancer in older patients: International Society of Geriatric Oncology (SIOG) consensus recommendations 2013. Ann Oncol 2015;26:463-76.

14 National Cancer Institute. Jointpoint regression program. Version 3.4.2. 2009 edition.

15 Roy HK, Bianchi LK. Differences in colon adenomas and carcinomas among women and men: potential clinical implications. JAMA 2009;302:1696-7.

16 Stock C, Haug U, Brenner H. Population-based prevalence estimates of history of colonoscopy or sigmoidoscopy: review and analysis of recent trends. Gastrointest Endosc 2010;71:366-81.e2.

17 Robb K, Stubbings S, Ramirez A, et al. Public awareness of cancer in Britain: a population-based survey of adults. Br/Cancer 2009;101(suppl 2):S18-23.

18 Quaife SL, Forbes LI, Ramirez AJ, et al. Recognition of cancer warning signs and anticipated delay in help-seeking in a population sample of adults in the UK. BrJ Cancer 2014;110:12-8.

19 Svensson E, Grotmol T, Hoff G, Langmark F, Norstein J, Tretli S. Trends in colorectal cancer incidence in Norway by gender and anatomic site: an age-period-cohort analysis. Eur J Cancer Prev 2002;11:489-95.

20 Wallace D, Walker K, Kuryba A, Finan P, Scott N, van der Meulen J. Identifying patients at risk of emergency admission for colorectal cancer. Br/Cancer 2014:111:577-80.

21 Bojer AS, Roikjaer O. Elderly patients with colorectal cancer are oncologically undertreated. Eur / Surg Oncol 2015;41:421-5.

22 McKay A, Donaleshen J, Helewa RM, et al. Does young age influence the prognosis of colorectal cancer: a population-based analysis. World J Surg Oncol 2014;12:370.

23 Rehm J, Gmel G. Alcohol consumption and public health in Russia. Lancet 2007;369:1975-6.

24 Rehm J, Sulkowska U, Manczuk M, et al. Alcohol accounts for a high proportion of premature mortality in central and eastern Europe. Int Epidemiol 2007:36:458-67.

25 Zaridze D, Brennan P, Boreham J, et al. Alcohol and cause-specific mortality in Russia: a retrospective case-control study of 48,557 adult deaths. Lancet 2009;373:2201-14.

26 Zatonski WA, Bhala N. Changing trends of diseases in Eastern Europe: closing the gap. Public Health 2012;126:248-52

27 Ondrusova M, Muzik J, Hrcka R, Friedova L, Ondrus D. Do we know the cause of the highest colorectal cancer incidence, the changes in the mortality trends and the clinical stages in the Slovak and Czech Republic, the representatives of the Central European region? Neoplasma 2011:58:283-90.

28 Schwingshackl L, Hoffmann G. Adherence to Mediterranean diet and risk of cancer: a systematic review and meta-analysis of observational studies. Int J Cancer 2014;135:1884-97.

29 Rodrigues SS, Caraher M, Trichopoulou A, de Almeida MD. Portuguese households' diet quality (adherence to Mediterranean food pattern and compliance with WHO population dietary goals): trends, regional disparities and socioeconomic determinants. Eur / Clin Nutr 2008;62:1263-72.

30 Bach-Faig A, Fuentes-Bol C, Ramos D, et al. The Mediterranean diet in Spain: adherence trends during the past two decades using the Mediterranean Adequacy Index. Public Health Nutr 2011;14:622-8.

31 Tourlouki E, Matalas AL, Bountziouka V, et al. Are current dietary habits in Mediterranean islands a reflection of the past? Results from the MEDIS study. Ecol Food Nutr 2013;52:371-86.

32 Bonaccio M, Di Castelnuovo A, Bonanni A, et al. Decline of the Mediterranean diet at a time of economic crisis. Results from the Moli-sani study. Nutr Metab Cardiovasc Dis 2014;24:853-60.

33 Boyle P, Leon ME. Epidemiology of colorectal cancer. Br Med Bull 2002;64:1-25

34 Kirkegaard H, Johnsen NF, Christensen J, Frederiksen K, Overvad K, Tjonneland A. Association of adherence to lifestyle recommendations and risk of colorectal cancer: a prospective Danish cohort study. BMJ 2010;341:c5504.
35 Mills KT, Bellows CF, Hoffman AE, Kelly TN, Gagliardi G. Diabetes mellitus and colorectal cancer prognosis: a meta-analysis. Dis Colon Rectum 2013:56:1304-19.

36 Peeters PJ, Bazelier MT, Leufkens HG, de Vries F, De Bruin ML. The risk of colorectal cancer in patients with type 2 diabetes: associations with treatment stage and obesity. Diabetes Care 2015;38:495-502.

37 Boniol M, Autier P. Prevalence of main cancer lifestyle risk factors in Europe in 2000. Eur J Cancer 2010;46:2534-44.

38 MacArthur C, Smith A. Delay in the diagnosis of colorectal cancer. J $R$ Coll Gen Pract 1983:33:159-61.

39 Hewitson P, Glasziou P, Irwig L, Towler B, Watson E. Screening for colorectal cancer using the faecal occult blood test, Hemoccult. Cochrane Database Syst Rev 2007;1:CD001216.

40 Elmunzer BJ, Hayward RA, Schoenfeld PS, Saini SD, Deshpande A Waljee AK. Effect of flexible sigmoidoscopy-based screening on incidence and mortality of colorectal cancer: a systematic review and meta-analysis of randomized controlled trials. PLoS Med 2012;9:e1001352.

41 Winawer SJ, Zauber AG, Ho MN, et al. Prevention of colorectal cancer by colonoscopic polypectomy. The national polyp study workgroup. N Engl J Med 1993;329:1977-81.

42 Nishihara R, Wu K, Lochhead P, et al. Long-term colorectal-cance incidence and mortality after lower endoscopy. N Engl J Med 2013:369:1095-105.

43 Altobelli E, Lattanzi A, Paduano R, Varassi G, di Orio F. Colorectal cancer prevention in Europe: Burden of disease and status of screening programs. Prev Med 2014;62C:132-41.

44 Binefa G, Rodriguez-Moranta F, Teule A, Medina-Hayas M. Colorectal cancer: from prevention to personalized medicine. World J Gastroenterol 2014:20:6786-808.

45 Kanavos P, Schurer W. The dynamics of colorectal cancer management in 17 countries. Eur J Health Econ 2010;10(suppl 1):S115-29.

46 Wilschut JA, Habbema JD, van Leerdam ME, et al. Fecal occult blood testing when colonoscopy capacity is limited. / Natl Cancer Inst 2011;103:1741-51.

47 Jezewski-Serra D, Salines E. Évaluation épidémiologique du programme de dépistage organisé du cancer colorectal en France. Institut de Veille Sanitaire, 2013.

48 Weiss W, Homoncik M. [Colorectal carcinoma in Austria: update 2008]. J Gastroenterol Hepatol Erkr 2008;6:19-22.

49 Pox CP, Altenhofen L, Brenner H, Theilmeier A, Von Stillfried D, Schmiegel W. Efficacy of a nationwide screening colonoscopy program for colorectal cancer. Gastroenterology 2012;142:1460-7.e2.

50 Stock C, Brenner H. Utilization of lower gastrointestinal endoscopy and fecal occult blood test in 11 European countries: evidence from the survey of health, aging and retirement in Europe (SHARE). Endoscopy 2010;42:546-56.

51 Espey DK, Wu XC, Swan J, et al. Annual report to the nation on the status of cancer, 1975-2004, featuring cancer in American Indians and Alaska Natives. Cancer 2007;110:2119-52.

52 Levin B, Lieberman DA, McFarland B, et al. Screening and surveillance for the early detection of colorectal cancer and adenomatous polyps, 2008: a joint guideline from the American Cancer Society, the US multi-society task force on colorectal cancer, and the American College of Radiology. CA Cancer J Clin 2008;58:130-60.

53 Cunningham D, Atkin W, Lenz HJ, et al. Colorectal cancer. Lancet 2010;375:1030-47

54 Oliphant R, Nicholson GA, Horgan PG, et al. Contribution of surgical specialization to improved colorectal cancer survival. Br J Surg 2013;100:1388-95

55 van der Pool AE, Damhuis RA, lizermans IN, et al. Trends in incidence, treatment and survival of patients with stage IV colorectal cancer: a population-based series. Colorectal Dis 2012;14:56-61.

56 Brenner H, Kloor M, Pox CP. Colorectal cancer. Lancet 2014;383:1490-502

57 Boyle P. Relative value of incidence and mortality data in cancer research. Recent Results Cancer Res 1989;114:41-63.

58 Harteloh P, de Bruin K, Kardaun J. The reliability of cause-of-death coding in The Netherlands. Eur J Epidemiol 2010;25:531-8.

(C) BMJ Publishing Group Ltd 2015

Web appendix: Supplementary material 